\title{
Análise da Produção Escrita de Estudantes do Ensino Superior: Uma Abordagem Semiótica
}

\author{
Written Production Analysis of Higher Education Students: A \\ Semiotic Approach
}

\author{
Victor Hugo dos Santos Gois ${ }^{\mathrm{a}}$; Karina Alessandra Pessoa da Silva ${ }^{\mathrm{a}}$; Jader Otavio Dalto \\ a Departamento Acadêmico de Matemática, Universidade Tecnológica Federal do Paraná, Londrina, Brasil - \\ victor.gois28@hotmail.com, karinasilva@utfpr.edu.br \\ b Departamento Acadêmico de Matemática, Universidade Tecnológica Federal do Paraná, Cornélio Procópio, Brasil - \\ jaderdalto@utfpr.edu.br
}

\section{Palavras-chave:}

Educação matemática. Cálculo diferencial e integral. Funções definidas por mais de uma sentença. Semiótica peirceana.
Resumo: Neste artigo trazemos resultados de uma investigação desenvolvida com alunos de Licenciatura em Química em uma disciplina de Cálculo Diferencial e Integral 1 cujo objetivo foi analisar as produções escritas, por meio dos signos produzidos em atividades que tratavam de funções definidas por mais de uma sentença. Assim, referenciais teóricos que tratam de semiótica, enquanto ciência dos signos, e reflexões a respeito da Análise da Produção Escrita em Matemática subsidiaram nossa análise de cunho qualitativo e interpretativo. As atividades analisadas foram resolvidas em sala de aula e compunham, junto a outras atividades, uma das três provas desenvolvidas ao longo do semestre letivo (regime semestral) e propostas ao final do estudo de um bloco de conteúdos. A prova cujas atividades foram analisadas foi a primeira a ser feita pelos estudantes e avaliava também o estudo de limites e continuidade. Os apontamentos que engendramos têm como premissa os signos escritos produzidos nas resoluções dos estudantes, em que pudemos evidenciar conhecimentos matemáticos, bem como identificar algumas fragilidades quanto ao conhecimento sobre funções definidas por mais de uma sentença.

\footnotetext{
Abstract: In this paper we present results of a research developed with students of Chemistry Degree in a discipline of Differential and Integral Calculus 1 whose objective was to analyze as written productions, through the signs produced in activities that deal with functions defined by more than one sentence. Thus, theoretical references dealing with semiotics as a science of signs and reflections on the Written Production Analysis in Mathematics have subsidized our qualitative and interpretative analysis. As analyzed activities were solved in the classroom and composed, along with other issues, one of the three tests developed during the semester (semester regime) and proposals at the end of the study of a block of contents. The test whose activities were analyzed was the first to be, made by the students and evaluated, also, the study of limits and continuity. The notes we generate have as a premise the written signs produced in student resolutions, in which we could know, as well as identify some weaknesses as to knowledge about the functions defined by more than one sentence.
} 


\section{Introdução}

Pesquisas têm apontado que, de forma geral, estudantes que ingressam em cursos do Ensino Superior, na área de exatas, apresentam fragilidades ${ }^{1}$ com alguns conteúdos matemáticos que estão inseridos no currículo do Ensino Médio de Matemática, em especial aqueles que envolvem o conceito de função e, com isso, apresentam dificuldades quando cursam disciplinas como a de Cálculo Diferencial e Integral.

Pensando nisso e considerando nossas experiências com discentes de Cálculo², entendemos que um conhecimento matemático que se faz basilar é o de funções definidas por mais de uma sentença em suas representações algébrica e gráfica, em suas interpretações e análises de fatos da realidade.

Ao fazer uma busca nas coleções de Livros Didáticos do Ensino Médio de Matemática aprovadas no Programa Nacional do Livro Didático, $2018^{3}$ (BRASIL, 2017) verificamos que cinco, das oito coleções, apresentam em seus sumários um capítulo, ou tópico, a respeito de funções definidas por mais de uma sentença (PAIVA, 2015; DANTE, 2016; IEZZI et all., 2016; MODERNA, 2016; SMOLE; DINIZ, 2016) o que reforça que há uma preocupação que este conteúdo seja tratado e explorado no Ensino Médio.

Depois de feita a pesquisa nos Livros Didáticos (LD) selecionamos duas atividades que abordam funções definidas por mais de uma sentença presentes em um desses livros e as inserimos em uma prova feita por estudantes de uma disciplina de Cálculo Diferencial e Integral 1, de um curso de Licenciatura em Química. Tal prova correspondia a uma das três realizadas pelos alunos durante o segundo semestre letivo (regime semestral) de 2017, proposta após o estudo dos conteúdos funções, limite e continuidade. Levando em consideração que produção escrita em matemática pode ser um dos subsídios do docente para inferir sobre os conhecimentos que os discentes têm de determinado tema, ou ainda, quais são as dificuldades que eles apresentam (CELESTE, 2008) é que nos debruçamos em evidenciar "o que revelam as Produções Escritas dos estudantes de Licenciatura em Química a respeito de funções definidas por mais de uma sentença em atividades contextualizadas e estritamente matemáticas?".

Para a análise consideramos, dentre outros, os signos presentes nos registros escritos dos estudantes e apresentados neste artigo que traz, além dessa introdução, nossos entendimentos a respeito da Semiótica de Peirce, seguida da análise da produção escrita dos alunos e finalizando com alguns apontamentos que fizemos.

\footnotetext{
${ }^{1}$ Entendemos por fragilidade, erros de conceituação, de rigor matemático ou desconhecimento de conteúdos matemáticos que os alunos trazem daquilo que está proposto no currículo de Matemática da Educação Básica.

${ }^{2}$ Em alguns momentos do texto utilizamos o termo Cálculo para nos referirmos a Cálculo Diferencial e Integral.

${ }^{3}$ O Guia PNLD 2018 foi disponibilizado para consulta no dia 02/08/2017.
} 


\section{Sobre semiótica peirceana}

A Semiótica é um campo de estudo considerado novo por muitos pesquisadores, no entanto, tem ocupado lugar de destaque crescente, principalmente, nas ciências sociais e humanas. Trata-se da ciência dos signos, os signos da linguagem. Pignatari (1981) apresenta a origem do termo signo:

[...] através do latim "signum", vem do étimo grego secnom, raiz do verbo "cortar", "extrair uma parte de" (naquele idioma) e que [...] a raiz primitiva parece indicar que "signo" seria algo que se referisse a uma coisa maior do que foi extraído: uma folha em relação a uma árvore, um dente em ralação a um bicho etc (PIGNATARI, 1981, p. 23).

Assim, podemos entender signo como a representação de algo para alguém. Segundo Charles Sanders Peirce (1839-1914), esse algo é chamado de objeto, interpretado por meio de um novo signo (interpretante) produzido na mente do intérprete (alguém). O novo signo (interpretante) pode se equiparar ao primeiro ou ser mais rebuscado (PEIRCE, 2012). Em suas interpretações da obra de Peirce, Santaella (2007, p. 7), afirma que "o signo é um primeiro (algo que se apresenta à mente), ligando um segundo (aquilo que o signo indica, se refere ou representa) a um terceiro (o efeito que o signo irá provocar em um possível intérprete)". Com isso, o signo estabelece mediação entre objeto e interpretante.

O objeto, para Peirce (2012, p. 48) é "uma coisa singular existente e conhecida ou que se acredita tenha anteriormente existido ou que se espera venha a existir". Ao relacionar o signo com o objeto, Bougnoux (1999), destaca que:

\footnotetext{
Dois traços notáveis do signo merecem ainda ser sublinhados, a abreviação e a idealidade. A primeira vantagem do signo é a abreviação. Codificar é abreviar, um signo é sempre mais breve do que a coisa à qual remete. Tomemos o exemplo típico do mapa, que não é o território; muito - mesmo infinitamente - mais simples do que este, o mapa torna-o, ao mesmo tempo, manejável e decidível. Lessis more (segundo a expressão célebre de Nicholas Negroponte), a informação é uma grandeza negativa, uma subtração infligida à complexidade do real (BOUGNOUX, 1999, p. 66).
}

Os estudos semióticos empreendidos por Peirce considera uma caracterização triádica dos elementos (signo, objeto e interpretante). Ao estabelecer relações entre signo com o objeto, em sua referência àquilo que representa, se refere ou indica, estabelece uma teoria da objetivação. Na objetivação, o signo estabelece-se três tipos de relação com o objeto: ícone, índice e símbolo.

Um ícone sugere ou evoca seu objeto, a qualidade que ele exibe se assemelha a outra qualidade. Ao caracterizar o signo como ícone Peirce (2012) diz que:

A única maneira de comunicar diretamente uma ideia é através de um ícone; e todo método de comunicação indireta de uma ideia deve depender, para ser estabelecido, do uso de um ícone. Daí segue-se que toda asserção deve conter um ícone ou conjunto de ícones, ou então deve conter signos cujo significado só seja explicável por ícones. A ideia significada por um conjunto de ícones (ou o equivalente a um conjunto de ícones) contido numa asserção pode ser denominada de predicado da asserção (PEIRCE, 2012, p. 64). 
Um índice indica seu objeto pela existência concreta. Santaella (2007), afirma que "os índices envolvem ícones. Mas não são os ícones que os fazem funcionar como signos” (p. 19). Por exemplo, a imagem da montanha apresentada em uma fotografia tem alguma semelhança com a aparência da montanha, daí temos um ícone. No entanto, a imagem é um índice, pois é o resultado de uma conexão de existência entre a fotografia e a montanha.

Quando se tem signos como índices há uma relação díade entre representâmen e objeto (NÖTH, 2008) e Peirce (2012) os caracteriza pela maneira que:

[...] podem distinguir-se de outros signos, ou representações, por três traços característicos: primeiro, não têm nenhuma semelhança significante com seus objetos; segundo, referem-se a individuais, unidades singulares, coleções singulares de unidades ou a contínuos singulares; terceiro, dirigem a atenção para seus objetos através de uma compulsão cega. Mas seria difícil, senão impossível, citar como exemplo um índice absolutamente puro, ou encontrar um signo qualquer absolutamente desprovido da qualidade indicial. Psicologicamente, a ação dos índices depende de uma associação por contiguidade, e não de uma associação por semelhança ou de operações intelectuais (PEIRCE, 2012, p. 75-76).

Um símbolo representa seu objeto, representa aquilo que a lei determina para que ele represente. Abordando o conceito de símbolo, Peirce (apud OTTE, 2001) argumenta que "Um símbolo é um signo convencional que associado a um objeto tem certos caracteres. Mas um símbolo, por si mesmo, é um mero sonho; não mostra sobre o que está falando. Precisa estar conectado a seu objeto" (p. 14).

Para Niemeyer (2003, p. 42) "mesmo onde a essência de um Símbolo é a de livre associação, essa associação não é arbitrária, mas determinada por princípios pré-existentes, inerentes ao tipo de código a que pertence o signo". Peirce caracteriza símbolo dizendo que:

A palavra Símbolo possui tantos significados que seria uma ofensa à língua acrescentar-lhe mais um. Creio que a significação que lhe atribuo, a de um signo convencional, ou de um signo que depende de um hábito (adquirido ou nato), não é tanto um novo significado, mas, sim, um retorno ao significado original. [...] Normalmente se diz que na palavra símbolo é preciso entender o "correr junto com" no sentido de "conjecturar"; mas, se fosse este o caso, deveríamos descobrir que algumas vezes, pelo menos, significaria uma conjectura, significado à cuja procura em vão vasculharíamos a literatura (PEIRCE, 2012, p. 72, grifos do autor).

Com isso, para que um símbolo represente algo, ele deve estar em conexão com um objeto. No contexto matemático, de nada adianta termos um símbolo gráfico, um registro gráfico traçado no papel se este não for associado a um objeto matemático.

Em nossa investigação focamos nosso olhar nos signos presentes na produção escrita de estudantes do Ensino Superior ao resolver uma prova em que se está presente o objeto matemático função definida por mais de uma sentença.

\section{Análise da produção escrita em matemática}

Um dos grupos precursores, senão o proto-pesquisador a respeito da Análise da Produção Escrita de alunos em Matemática como uma prática investigativa, é o GEPEMA - 
Grupo de Estudos e Pesquisa em Educação Matemática e Avaliação - que cumula uma gama de pesquisas de dissertações e teses envolvendo essa temática e suas relações com alunos e professores (p. ex. DALTO, 2007; ALMEIDA, 2009; PIRES, 2013).

Desde 2004, esse grupo de estudos desenvolve pesquisas que tratam a respeito dessa temática, que busca esclarecer e tentar entender o que a produção escrita de professores e estudantes revela, ou o que esses diferentes sujeitos nos processos de ensino e aprendizagem pensam na hora de resolver atividades matemáticas que são rotineiras e que não são rotineiras (SANTOS; BURIASCO, 2015).

Segundo Santos (2008):

Toda produção escrita dos estudantes, seja ela obtida por meio de trabalhos, provas ou qualquer outro instrumento que possibilite o registro de suas idéias, é importante, pois, ao analisar e interpretar, por exemplo, a produção escrita dos estudantes na resolução de um problema, o professor pode perceber que, por meio dessa resolução, seja ela considerada totalmente correta, parcialmente correta ou incorreta, é possível obter informações sobre o que eles sabem do conteúdo envolvido, ter pistas do que podem vir a saber futuramente (SANTOS, 2008, p. 20)

Para analisar as produções escritas, o GEPEMA tem utilizado, em suas pesquisas, uma série de etapas, das quais as mais frequentes são leitura vertical, leitura horizontal, inferência e interpretação. A leitura vertical busca olhar para todas as produções que um aluno fez, na tentativa de traçar um perfil de quais são as dificuldades e estratégias que esse aluno tem para resolver as situações propostas a ele. Por outro lado, a leitura horizontal é realizada quando o foco são as resoluções de um grupo de alunos a respeito de uma única atividade, buscando-se traçar um perfil das estratégias e procedimentos utilizados por essa turma e quais são suas dificuldades (SANTOS; BURIASCO, 2015).

A inferência, para Santos e Buriasco (2015, p. 122) "busca ir além do que é encontrado na produção do aluno para tentar complementar informações a respeito do seu modo de lidar que não estão visíveis à primeira vista”. E, a quarta etapa, a interpretação "auxilia a compreender como os alunos lidam com as atividades. Constitui-se em movimentos para tentar atribuir significados à produção escrita analisada" (SANTOS; BURIASCO, 2015, p. 122)".

Assim,

[...] a análise da produção escrita não tem como objetivo a atribuição de uma nota ou um conceito. O objetivo está em obter informações que possibilitem uma tomada de consciência do ocorrido nos processos de ensino e de aprendizagem e de decisão de modo a auxiliar tanto professor quanto estudantes a organizar e orientar seus trabalhos (SANTOS; BURIASCO, 2016, p. 240).

Levando em consideração esses apontamos, apresentamos, a seguir, os aspectos metodológicos de nossa investigação que apresentam como os dados foram codificados, agrupamentos feitos, dentre outras informações relevantes que nos possibilitassem inferir sobre o conhecimento dos alunos a partir de suas produções escritas. 


\section{Aspectos metodológicos da nossa investigação}

Para investigar o que revelam as produções escritas dos estudantes de Licenciatura em Química a respeito de funções definidas por mais de uma sentença em atividades contextualizadas e em atividades estritamente matemáticas em uma prova de Cálculo, nos apoiamos no referencial teórico apresentado e na produção escrita de quarenta estudantes.

A primeira prova da disciplina feita pelos alunos após o estudo do conteúdo matemático analisado consistia de 10 atividades que tratavam dos conceitos de: funções definidas por mais de uma sentença, limites e continuidade. Nossa atenção se volta para as atividades específicas de função definida por mais de uma sentença - Atividades 1, 2, 5 e 6 (Quadro 1), ou seja, uma função que para cada subdomínio $\mathrm{D}_{1}, \mathrm{D}_{2}, \ldots, \mathrm{D}_{n}$ está definida uma sentença; a união destes $n$ subdomínios forma o domínio D da função original, ou seja, cada domínio $\mathrm{D}_{n}$ é um subconjunto de $\mathrm{D}$.

As duas primeiras atividades se relacionam e as consideramos como estritamente matemáticas - cujo contexto é estritamente matemático; no caso, abordam aspectos algébricos - e as atividades 5 e 6 também se relacionam e tratam de atividades contextualizadas - que abordam situações-problema em contextos extra-matemáticos.

As atividades 1 e 5 foram retiradas de um livro didático do Ensino Médio aprovado pelo PNLD 2018 - Iezzi et al. (2016) e as atividades 2 e 6 foram propostas pela professora (segunda autora deste artigo) da turma com o intuito de requerer a produção de signos gráficos.

Quadro 1 - Atividades analisadas

1) Seja $f: \mathfrak{R} \rightarrow \mathfrak{R}$ definida por:

$$
f(x)= \begin{cases}2 x, & \text { se } x<-2 \\ x+3, & \text { se }-2 \leq x<1 \\ x^{2}-5, & \text { se } x \geq 1\end{cases}
$$

Calcule o valor de:
a) $f(-3)+f(0)$
c) $f(-2) \cdot f(2)$
b) $f(\sqrt{3})-f(-1)$

2) Faça a representação gráfica da função da questão 1.

a) Explicite o domínio e a imagem da função.

b) A função $f$ possui limite quando $x$ tende a -2 ?

E quando $x$ tende a 1? Justifique sua resposta por meio de cálculos.
5) Uma operadora de celular oferece dois planos a seus clientes:

- Plano I: valor fixo mensal de $\mathrm{R} \$ 80,00$ para até 120 minutos de ligações locais. Caso o cliente exceda esse tempo, o custo do minuto adicional é de $\mathrm{R} \$ 1,20$.

- Plano II: não há mensalidade e cada ligação local custa $R \$ 0,80$, o minuto.

Para quantos minutos de ligações locais no mês é indiferente contratar qualquer um dos planos?

6) Represente graficamente a situação apresentada na questão 5 .

Fonte: Iezzi et al. (2016, p. 117) e autores.

Embora neste artigo nos debruçássemos sobre os signos produzidos pelos alunos nas quatro atividades supracitadas, realizamos uma análise das produções escritas de todos os alunos para todas as atividades da prova. Com isso, codificamos as produções escritas com 
letras e números. Ao tratarmos, por exemplo, da produção A33ATIV02, esta pertence ao trigésimo terceiro aluno na segunda atividade. Num total foram obtidas 40 produções, que geraram 400 códigos.

As produções escritas para cada atividade foram organizadas em três agrupamentos:

- responderam corretamente - a resolução do aluno era colocada nesse grupo quando estava totalmente correta, apresentando resolução e resposta corretas;

- responderam equivocadamente - quando o que foi apresentado pelo aluno está parcialmente correto, mas há divergências com o que era esperado pela atividade. Respostas incompletas são exemplo de códigos que foram selecionados para esse grupo;

- não responderam - nesse terceiro grupo, foram selecionadas as atividades não feitas pelo aluno, ou se apenas registrou as informações presentes na atividade e não apresentou qualquer tipo de encaminhamento para a mesma.

$\mathrm{Na}$ análise feita por meio da semiótica de Peirce, perpassamos pelas etapas da Análise da Produção Escrita (leituras, inferência e interpretação). Durante a leitura vertical destacamos alguns signos produzidos pelos alunos e, para isso, selecionamos as produções escritas dos alunos A11, A16, A27 e A37. A seleção desses alunos se justifica, por: A16 apresentar resolução para todas as atividades analisadas e quase todas elas agrupadas como "Responderam corretamente"; A27 e A37 apresentaram signos em sua maioria agrupados como "Responderam equivocadamente"; e A11 teve quase todos seus códigos no agrupamento "Não responderam". Assim, pudemos destacar signos produzidos em códigos presentes nos três agrupamentos.

Do ponto de vista metodológico, trata-se de uma pesquisa qualitativa e de análise interpretativa, conforme Bogdan e Biklen (1994). Para os autores, a pesquisa qualitativa apresenta cinco características básicas: ambiente natural como fonte direta de dados e o pesquisador como seu principal instrumento; os dados coletados são predominantemente descritivos; a preocupação com o processo é maior do que com o produto; o "significado" dado pelas pessoas às coisas e à vida é de atenção especial para o pesquisador; a análise dos dados tende a seguir um processo indutivo.

Assim, em nossa investigação o ambiente de coleta de dados foi uma sala de aula de uma disciplina de Cálculo Diferencial e Integral 1, com estudantes de Licenciatura em Química orientados e avaliados por um professor (pesquisador). Os dados coletados e analisados correspondem a registros escritos dos alunos na resolução da primeira prova feita após o estudo do conteúdo matemático. A análise organizou-se em torno da codificação dos dados, exploração (a partir da correção das atividades e agrupamento das mesmas), tratamento 
do material (por meio da semiótica e dos signos produzidos pelos alunos) e interpretação dos dados.

Nas próximas seções apresentamos a leitura vertical, horizontal e inferência que fizemos das produções escritas dos alunos nas quatro atividades analisadas para, em seguida, elucidarmos nossas interpretações nas ponderações finais deste artigo.

\section{As Atividades Estritamente Matemáticas}

Levando em consideração nossos referenciais teóricos, inicialmente fizemos uma leitura vertical das resoluções de todos os alunos para todas as atividades. Nessa seção apresentamos uma análise da produção escrita para as atividades 1 e 2 (Quadro 1) que caracterizamos como estritamente matemáticas.

As produções escritas de A16 foram inseridas no agrupamento "Resolveram corretamente" e estão apresentadas nas Figuras 1 e 2.

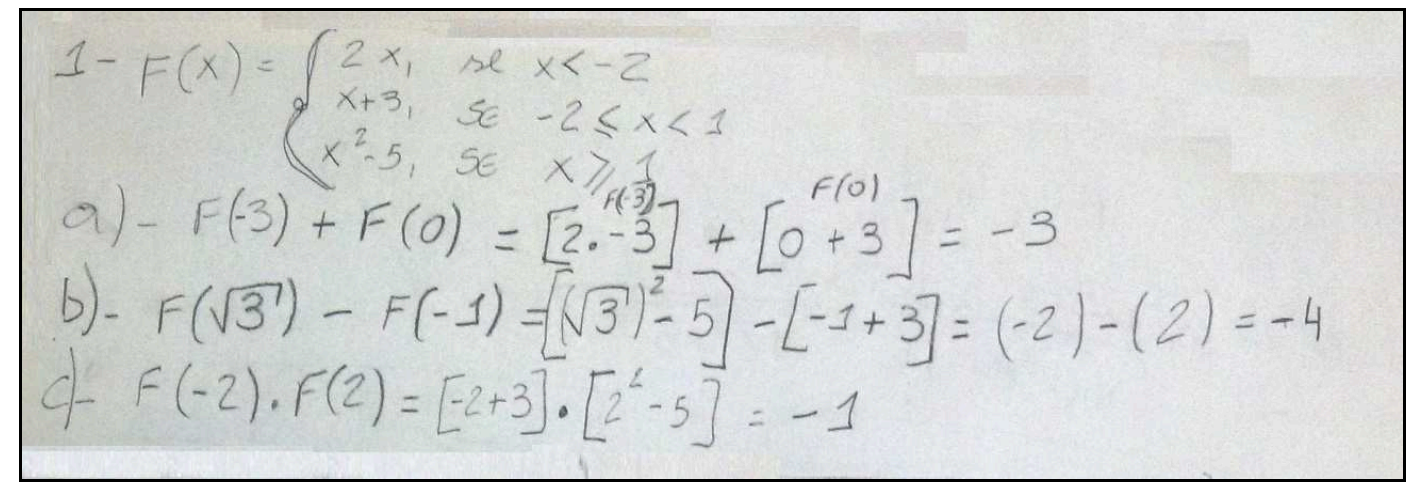

Figura 1 - Produção escrita A16ATIV01

Fonte: prova escrita do aluno A16.

Ao analisar a produção escrita de A16, pudemos inferir que este faz uso de signos na linguagem aritmética e esses signos se configuram como ícones do objeto matemático função definida por mais de uma sentença. Isso se deve ao fato de que tais signos "não se assemelham de modo algum aos seus objetos quanto à aparência; a semelhança entre eles consiste apenas da relação entre suas partes" (CP, 2.282 $\left.{ }^{4}\right)$.

Todavia, os signos produzidos por A16 também podem ser tratados como índices, quando A16 escreve:

$$
\begin{aligned}
& -[2 \cdot(-3)]+[0+3]=-3 \\
& \text { - }\left[(\sqrt{3})^{2}-5\right]-[(-1)+3]=(-2)-2=-4
\end{aligned}
$$

\footnotetext{
${ }^{4}$ Collected Papers of Charles Sanders Peirce, Ed. Charles Hartshorne e Paul Weiss (vols. I-IV: 1931/35). Harvard University Press, Cambridge, Mass., 1965; Ed. Arthur Burks (vols. VII-VIII: 1958), id., 1966. Para a citação cf. 2.282 (o primeiro dígito sinaliza o volume da obra referida e os demais o parágrafo. A obra é denotada usualmente pela sigla $\mathrm{CP}$ ).
} 
- $[-2+3] \cdot\left[2^{2}-5\right]=-1[-2+3] \cdot\left[2^{2}-5\right]=-1$

Segundo Peirce:

Os índices podem distinguir-se de outros signos ou representações por três traços característicos: primeiro, não têm nenhuma semelhança com seus objetos; segundo, referem-se a individuais, unidades singulares, coleções singulares de unidades ou a contínuos singulares; terceiro, dirigem a atenção para os seus objetos através de compulsão cega (CP, 2.306).

Da mesma forma, quando o aluno escreve $f(-3)$ e $f(0)$ em cima das expressões $[2 \cdot(-3)]$ e $[0+3]$, respectivamente, os signos $f(-3)$ e $f(0)$ correspondem a ícones, pois do modo como foram registrados remetem ao aluno às expressões $[2 \cdot(-3)]$ e $\left[\begin{array}{ll}0 & +3\end{array}\right.$.

O signo gráfico produzido na atividade 2 de A16, Figura 2, é um signo icônico, pois remete a uma representação da função tratada. E para a resolução dos itens a e b da segunda atividade há signos simbólicos quando o aluno faz uso de linguagem algébrica para respondêlos, pois para Peirce "um símbolo é um signo que se refere ao objeto que denota, em virtude de uma lei, normalmente uma associação de idéias gerais" (CP, 2.449).

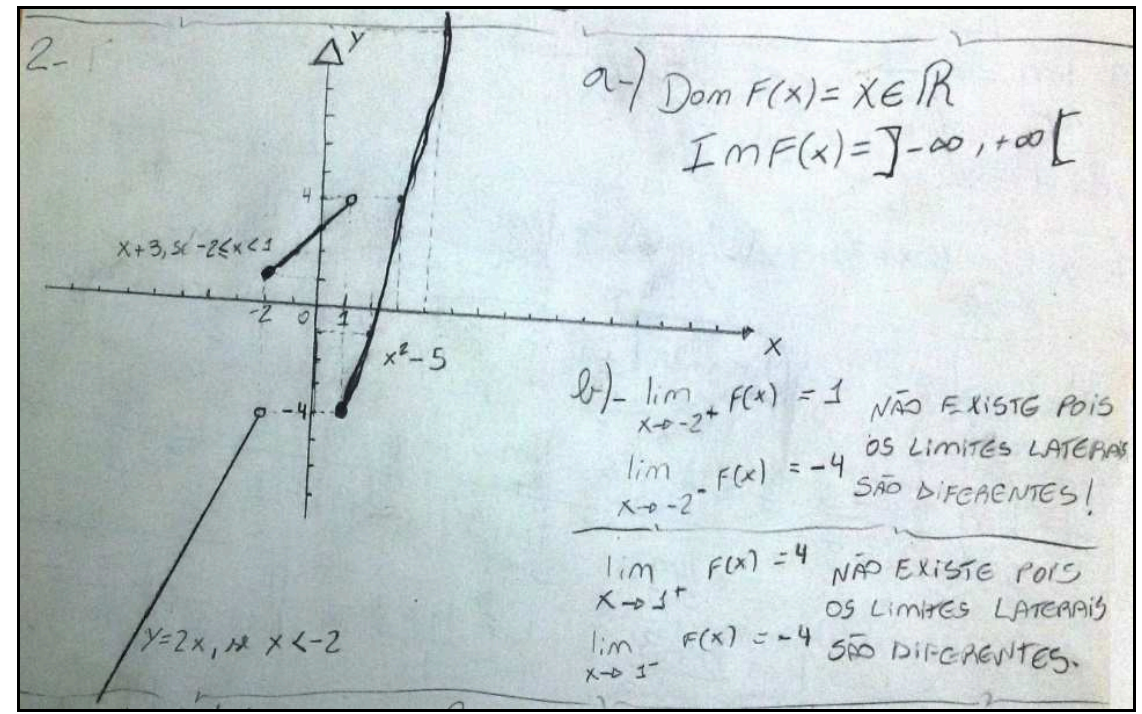

Figura 2 - Produção escrita A16ATIV02

Fonte: prova escrita do aluno A16.

Mas o que esses diferentes signos produzidos e suas relações com o objeto função definida por mais de uma sentença, apresentado no enunciado da atividade 1, revelam enquanto leitura vertical da produção escrita do aluno?

Segundo uma análise semiótica, por meio do uso de signos icônicos A16 mostra compreender o que é solicitado na atividade e pelos signos indiciais e simbólicos que produz consegue generalizar e mostrar conhecimento com relação ao objeto matemático estudado.

Contudo esse foi o único aluno que conseguiu resolver as duas atividades sem dificuldades. Alunos, assim como A27, apresentaram equívocos nas duas atividades. Nas Figuras 3 e 4 é possível evidenciar que A27 respondeu as atividades 1 e 2 juntas. 


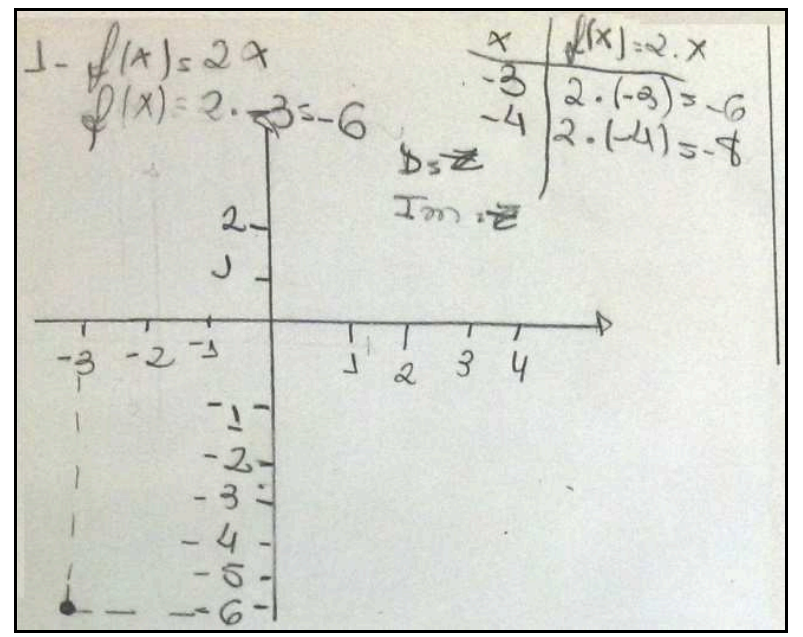

Figura 3 - Produção escrita de A27ATIV01/A27ATIV02

Fonte: prova escrita do aluno A27.

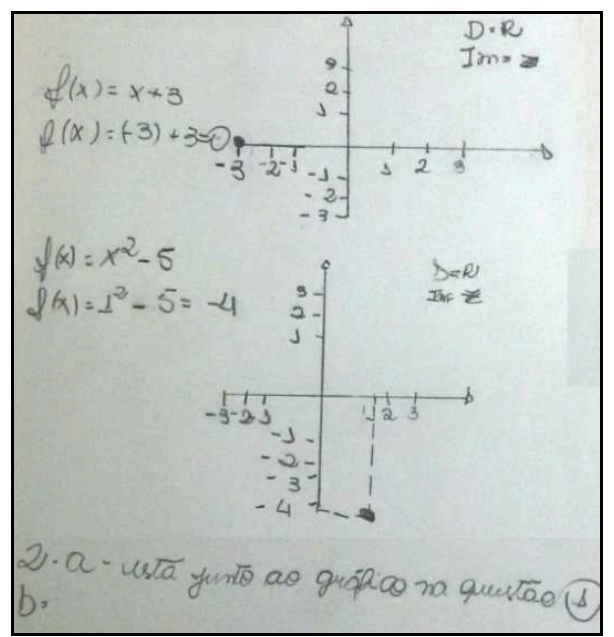

Figura 4 - Produção escrita de A27ATIV01/A27ATIV02

Fonte: prova escrita do aluno A27.

Os signos escritos não correspondem a uma solução correta para a atividade 1, mas mostram que A27 tenta de alguma maneira resolver parcialmente a atividade 2. Quando apresenta o signo tabela na Figura 3 (canto superior direito) associando valores de $x$ para a lei de formação $f(x)=2 x$, A27 explicita que necessita de tabelas para a produção de signos gráficos, e faz uso correto deste recurso, a associação no plano cartesiano do ponto $(-3,-6)$ no signo gráfico, também presente na Figura 4, corrobora com isso.

Contudo, o aluno representa graficamente um dos pontos que determinou na tabela no plano cartesiano (Figura 4) e não termina de traçar o gráfico da função. Além disso, por meio dos signos gráficos presentes na Figura 3 e na Figura 4 é possível evidenciar que A27 entende que cada sentença da função $f$ deva ser apresentada em um plano cartesiano. O que indica isso são os signos $f(x)=2 x, f(x)=x+3$ e $f(x)=x^{2}-5$, cada um próximo de cada um dos três signos gráficos no plano cartesiano.

Para responder o item a, da atividade 2, o discente identifica domínio e imagem da função $f$ em cada um dos signos gráficos, como se fossem três funções distintas. Entretanto, A27 identifica domínio e imagem no conjunto dos números Inteiros para a primeira sentença e, para as outras duas sentenças, domínio no conjunto dos números Reais e imagem no conjunto dos números Inteiros. Todavia, por meio dos signos produzidos não ficam evidentes o porquê das respostas dadas e qual a justificativa para diferenciar apenas a primeira sentença.

Em tela, A27 apresenta signos icônicos quando traça os planos cartesianos, ainda que não trace os gráficos, pois as "qualidades são semelhantes às do objeto e excitam sensações na mente para a qual é uma semelhança" (CP, 4.531); além disso, engendra signos indiciais quando considera:

- $f(x)=2 \cdot-3=-6$ 
- $f(x)=(-3)+3=0$

- $f(x)=1^{2} \cdot(-5)=-4$;

pois “força a atenção para o objeto específico pretendido sem descrevê-lo" (CP, 1.369).

A27 também apresenta signos simbólicos quando escreve "D=Z", "D=R" e "Im=Z", pois segundo Nöth, (2008, p. 83) para signos simbólicos "a relação entre Representâmen e objeto é arbitrária e depende de convenções sociais". Nesse caso as convenções matemáticas estabelecem “ $Z$ ” e " $R$ ” como representações dos conjuntos dos números Inteiros e dos números Reais, respectivamente.

A produção escrita do aluno A37 apresentada na Figura 5 denota que o aluno fez uso de três signos gráficos representados em três planos cartesianos distintos. Além disso, os signos gráficos produzidos correspondem a retas, e alguns pontos marcados nelas, mas não há associação alguma se são três gráficos e o porquê há três sentenças na função $f$ (um gráfico para cada sentença).
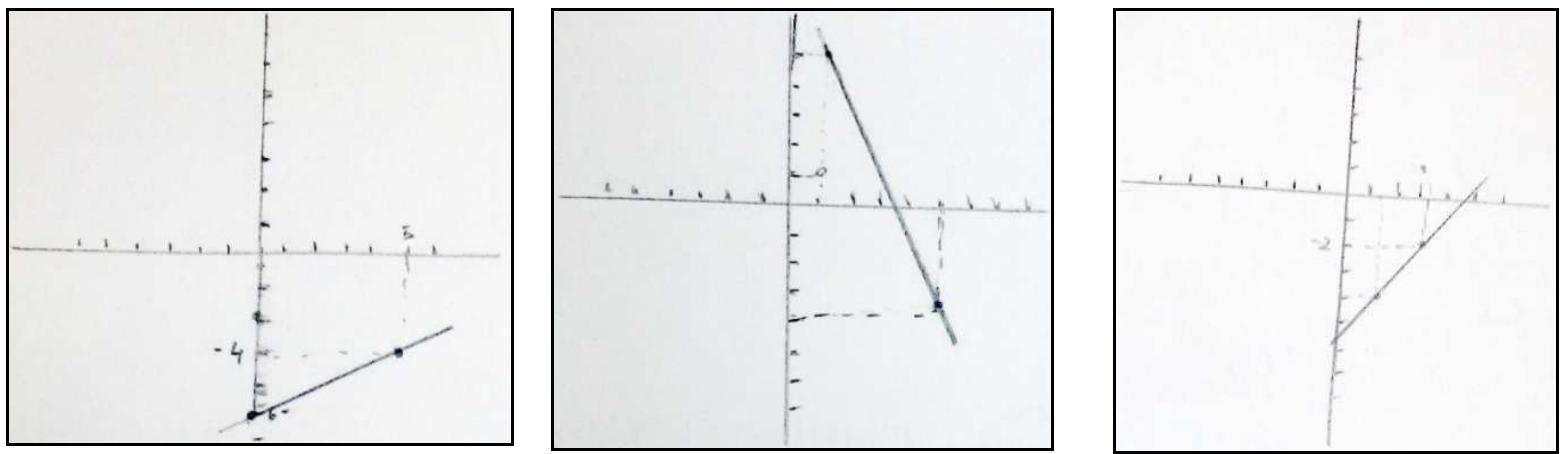

Figura 5 - Produção escrita de A37ATIV01/A37ATIV02

Fonte: prova escrita de A37.

A37 apresenta signos gráficos icônicos, pois esses remetem a uma representação da função, a gráfica. Todavia os signos produzidos apresentam equívocos em relação à lei de formação ao qual está associado.

Fazendo uma leitura horizontal das produções escritas da turma podemos observar na Tabela 1 como os dados foram agrupados para a atividade 1.

Olhando de maneira quantitativa para os dados agrupados, com as frequências e respectivas porcentagens de dados, apresentamos a Tabela 2, que sintetiza os dados agrupados na Tabela 1. 
Tabela 1 - Agrupamento das resoluções da atividade 1

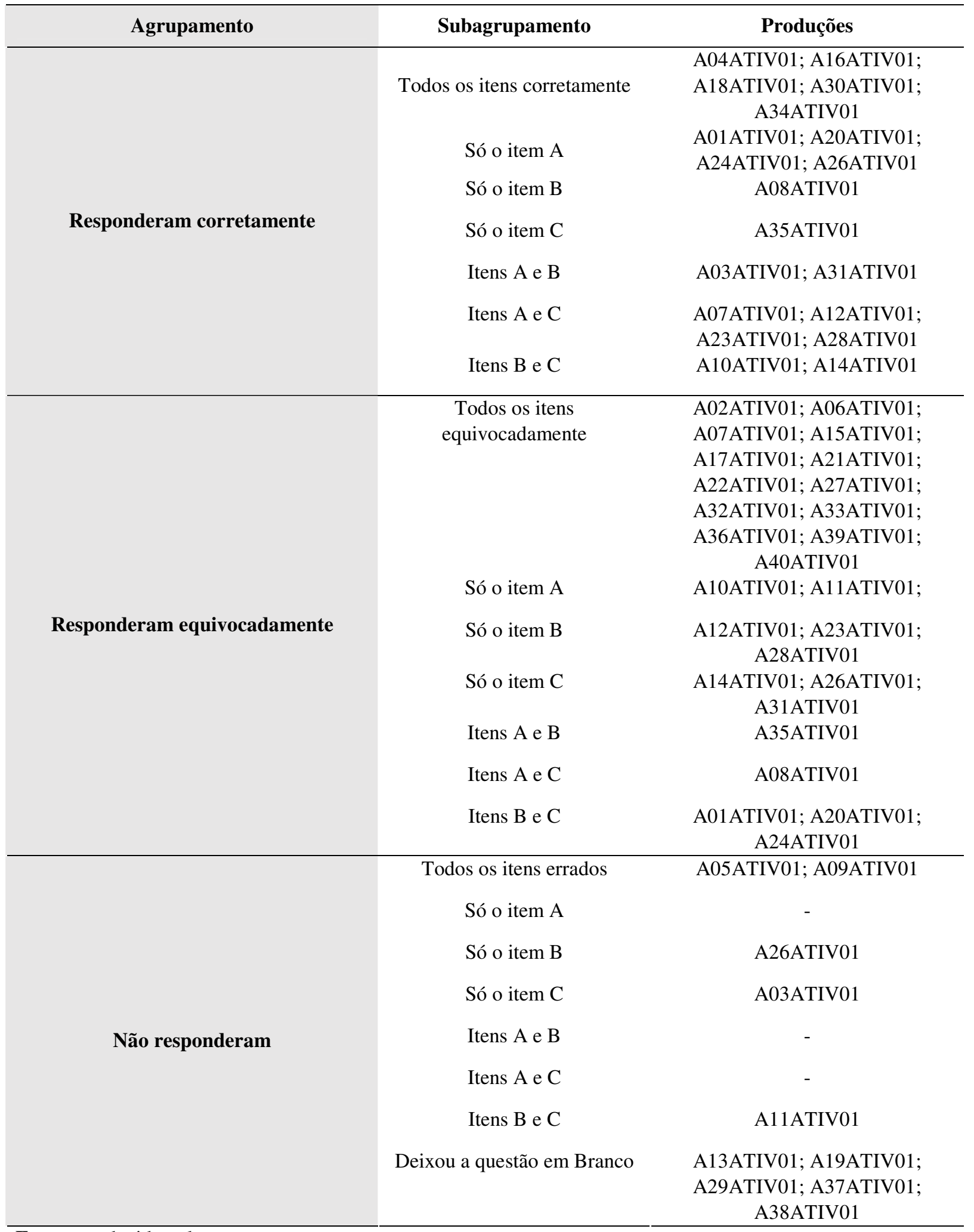

Fonte: produzido pelos autores. 
Tabela 2 - Dados quantitativos para o agrupamento das resoluções da atividade 1

\begin{tabular}{|c|c|c|c|}
\hline Agrupamento & Subagrupamento & $\begin{array}{l}\text { Número de } \\
\text { registros }\end{array}$ & $\begin{array}{c}\text { Porcentagens } \\
\text { em relação a } \\
\text { turma }\end{array}$ \\
\hline \multirow{7}{*}{$\begin{array}{l}\text { Responderam } \\
\text { corretamente }\end{array}$} & $\begin{array}{l}\text { Todos os itens } \\
\text { Corretamente }\end{array}$ & 5 & 12,5 \\
\hline & Só o item A & 4 & 10 \\
\hline & Só o item B & 1 & 2,5 \\
\hline & Só o item C & 1 & 2,5 \\
\hline & Itens A e B & 2 & 2,5 \\
\hline & Itens $\mathrm{A}$ e $\mathrm{C}$ & 4 & 10 \\
\hline & Itens B e C & 2 & 5 \\
\hline \multirow{8}{*}{$\begin{array}{c}\text { Responderam } \\
\text { equivocadamente }\end{array}$} & TOTAL & 19 & 45 \\
\hline & Todos os itens equivocadamente & 13 & 32,5 \\
\hline & Só o item A & 2 & 5 \\
\hline & Só o item B & 3 & 7,5 \\
\hline & Só o item C & 3 & 7,5 \\
\hline & Itens A e B & 1 & 2,5 \\
\hline & Itens $\mathrm{A}$ e $\mathrm{C}$ & 1 & 2,5 \\
\hline & Itens $\mathrm{B}$ e C & 3 & 7,5 \\
\hline \multicolumn{2}{|r|}{ TOTAL } & 26 & 65 \\
\hline \multirow{9}{*}{ Não responderam } & Todos os itens errados & 2 & 5 \\
\hline & Só o item A & 0 & 0 \\
\hline & Só o item B & 1 & 2,5 \\
\hline & Só o item C & 1 & 2,5 \\
\hline & Itens A e B & 0 & 0 \\
\hline & Itens $\mathrm{A}$ e $\mathrm{C}$ & 0 & 0 \\
\hline & Itens B e C & 1 & 2,5 \\
\hline & $\begin{array}{c}\text { Deixou a questão } \\
\text { em Branco }\end{array}$ & 5 & 12,5 \\
\hline & TOTAL & 10 & 25 \\
\hline
\end{tabular}

Fonte: produzido pelos autores.

Desse modo podemos inferir que a maioria dos alunos respondeu com equívocos a primeira atividade (26 registros), não sendo um item ou outro, mas boa parte respondeu totalmente equivocada (13 registros). Isso mostra uma fragilidade da turma no que diz respeito a associar corretamente os valores numéricos às sentenças da função.

Além disso, no agrupamento "Não responderam", a maioria das produções (5 registros) estava no subagrupamento "Deixou a questão em branco", ou seja, cinco alunos não tentaram registrar de maneira alguma uma resolução para a atividade.

A Tabela 3 apresenta erros que foram percebidos na resolução dos alunos para a atividade 1 e que corroboram para inferirmos a dificuldade que os alunos têm com o objeto matemático função definida por mais de uma sentença. 
Tabela 3 -Tipos de erros apresentados pelos alunos na atividade 1

\begin{tabular}{|c|c|c|}
\hline Códigos & Tipos de erros & $\begin{array}{c}\text { Porcentagem } \\
\text { em relação a } \\
\text { turma }\end{array}$ \\
\hline $\begin{array}{l}\text { A01ATIV01; A09ATIV01; A10ATIV01; } \\
\text { A11ATIV01; A14ATIV01; A17ATIV01; } \\
\text { A21ATIV01; A24ATIV01; A25ATIV01; } \\
\text { A27ATIV01; A31ATIV01; A36ATIV01; } \\
\text { A39ATIV01 }\end{array}$ & $\begin{array}{l}\text { Associar valor numérico à sentença } \\
\text { errada da função. }\end{array}$ & 32,5 \\
\hline A02ATIV01; A22ATIV01 & $\begin{array}{l}\text { Resposta como uma expressão } \\
\text { algébrica. }\end{array}$ & 5 \\
\hline A06ATIV01; A12ATIV01; A21ATIV01 & $\begin{array}{l}\text { Não sabia a qual sentença associar a } \\
\text { raiz quadrada de três. }\end{array}$ & 7,5 \\
\hline $\begin{array}{c}\text { A06ATIV01; A07ATIV01; A08ATIV01; } \\
\text { A23ATIV01; A24ATIV01; A25ATIV01; } \\
\text { A26ATIV01; A28ATIV01; A33ATIV01; } \\
\text { A36ATIV01 }\end{array}$ & $\begin{array}{l}\text { Erro na operação entre positivos e } \\
\text { negativos (operações de soma, } \\
\text { subtração e multiplicação). }\end{array}$ & 25 \\
\hline A10ATIV01; A14ATIV01 & $\begin{array}{l}\text { Confundiu }-3 \text { com } 3 \text { e associou a } \\
\text { sentença errada da função. }\end{array}$ & 5 \\
\hline A15ATIV01; A32ATIV01 & $\begin{array}{l}\text { Substituiu os valores numéricos dos três } \\
\text { itens nas três sentenças da função. }\end{array}$ & 5 \\
\hline A33ATIV01 & $\begin{array}{l}\text { Entendeu qual sentença utilizar, mas na } \\
\text { hora de resolver a copiou errada. }\end{array}$ & 2,5 \\
\hline
\end{tabular}

Fonte: produzido pelos autores.

Do mesmo modo, fazendo uma leitura horizontal da turma na resolução da atividade 2 podemos inferir por meio da Tabela 4 que a maioria das produções se concentra no agrupamento "Responderam equivocadamente" e mais especificamente no subagrupamento "Todos os itens equivocadamente". Essa leitura do perfil da turma na atividade 2 só complementa o que foi visto para a primeira atividade. Isso nos mostra que a turma tem dificuldades tanto algébricas quanto gráficas em resolver atividades que tratam de função definida por mais de uma sentença.

Olhando de maneira quantitativa para os dados agrupados, com as frequências e respectivas porcentagens de dados, apresentamos a Tabela 5.

Podemos inferir a partir dos dados da Tabela 5 que, na atividade 2, 12 registros foram agrupados como "Responderam corretamente", enquanto 27 registros foram agrupados como "Responderam equivocadamente" e 21 registros agrupados como "Não responderam”. Assim, podemos traçar um perfil da turma para essa atividade com uma dificuldade em resolvê-la e apresentando equívocos ou uma evasão considerável.

Além disso, no subagrupamento "Só o gráfico" foram alocados três registros que apresentaram equívocos na representação gráfica que fizeram, ou seja, não apresentaram dificuldades nas manipulações algébricas da função, mas tiveram dificuldades em representar graficamente. 
Tabela 4 - Agrupamento das resoluções da Atividade 2

\begin{tabular}{|c|c|c|}
\hline Agrupamento & Subagrupamento & Produções \\
\hline \multirow{3}{*}{ Responderam corretamente } & Todos os itens corretamente & A16ATIV02 \\
\hline & Só o item A & $\begin{array}{c}\text { A02ATIV02; A06ATIV02; A18ATIV02; } \\
\text { A23ATIV02; A25ATIV02; A28ATIV02; } \\
\text { A30ATIV02; A33ATIV02; A34ATIV02; } \\
\text { A39ATIV02 }\end{array}$ \\
\hline & Só o item B & A03ATIV02 \\
\hline \multirow{4}{*}{$\begin{array}{l}\text { Responderam } \\
\text { equivocadamente }\end{array}$} & $\begin{array}{l}\text { Todos os itens } \\
\text { equivocadamente }\end{array}$ & $\begin{array}{l}\text { A04ATIV02; A08ATIV02; A10ATIV02; } \\
\text { A12ATIV02; A14ATIV02; A15ATIV02; } \\
\text { A17ATIV02; A20ATIV02; A21ATIV02; } \\
\text { A22ATIV02; A24ATIV02; A27ATIV02; } \\
\text { A32ATIV02; A35ATIV02; A37ATIV02 }\end{array}$ \\
\hline & Só o item A & A03ATIV02 \\
\hline & Só o item B & $\begin{array}{l}\text { A01ATIV02; A02ATIV02; A23ATIV02; } \\
\text { A25ATIV02; A30ATIV02; A31ATIV02; } \\
\text { A33ATIV02; A39ATIV02 }\end{array}$ \\
\hline & Só o gráfico* & A28ATIV02; A30ATIV02; A34ATIV02 \\
\hline \multirow{4}{*}{ Não responderam } & Todos os itens errados & A37ATIV02 \\
\hline & Só o item A & $\begin{array}{l}\text { A04ATIV02; A12ATIV02; A17ATIV02; } \\
\text { A24ATIV02 }\end{array}$ \\
\hline & Só o item B & $\begin{array}{l}\text { A06ATIV02; A15ATIV02; A18ATIV02; } \\
\text { A20ATIV02; A21ATIV02; A27ATIV02 }\end{array}$ \\
\hline & Deixou a questão em Branco & $\begin{array}{c}\text { A05ATIV02; A07ATIV02; A09ATIV02; } \\
\text { A11ATIV02; A13ATIV02; A19ATIV02; } \\
\text { A26ATIV02; A36ATIV02; A38ATIV02; } \\
\text { A40ATIV02 }\end{array}$ \\
\hline
\end{tabular}

Fonte: produzido pelos autores.

Tabela 5 - Dados quantitativos para o agrupamento da Atividade 2

\begin{tabular}{cccc}
\hline Agrupamento & Subagrupamento & Número de registros & Porcentagens em relação ao todo \\
\hline \multirow{2}{*}{$\begin{array}{c}\text { Responderam } \\
\text { corretamente }\end{array}$} & Todos os itens corretamente & 01 & 2,5 \\
& Só o item A & 10 & 25 \\
& Só o item B & 01 & 2,5 \\
\hline \multirow{4}{*}{$\begin{array}{c}\text { Responderam } \\
\text { equivocadamente }\end{array}$} & Todos os itens & 15 & 37,5 \\
& equivocadamente & 01 & 2,5 \\
& Só o item A & 08 & 20 \\
& Só o item B & 03 & 7,5 \\
\hline \multirow{4}{*}{ Não responderam } & Só o gráfico* & 01 & 2,5 \\
& Todos os itens errados & 04 & 10 \\
& Só o item A & 06 & 15 \\
& Só o item B & 10 & 25 \\
\hline
\end{tabular}

Fonte: produzido pelos autores.

A partir das leituras vertical e horizontal da produção escrita dos alunos para as atividades 1 e 2 podemos inferir que a partir dos signos produzidos, os discentes denotam dificuldades em resolver algebricamente e graficamente funções definidas por mais de uma sentença em atividades estritamente matemáticas. Muitos alunos mostraram não saber como associar valores numéricos às sentenças corretas da lei de formação da função e ainda como construir um gráfico a partir de mais de uma sentença. 
Por outro lado, é possível inferir que a maioria dos alunos manipulam corretamente representações aritméticas, substituindo o valor de $x$ na função $f$. É possível evidenciar também que os alunos tinham conhecimentos prévios a respeito de funções, pois, por meio das produções escritas, os discentes apresentaram signos relacionados ao domínio e à imagem de uma função, eixos cartesianos para representação gráfica e a construção de quadros para, a partir de alguns valores arbitrários da abscissa, determinar valores de ordenadas.

\section{As atividades contextualizadas}

De forma análoga às duas atividades anteriores, apresentamos nossas análises semióticas dos signos produzidos pelos estudantes em outras duas atividades: uma contextualizada que fora também retirada de Iezzi et al. (2016) e uma elaborada pela professora da turma que tratava da representação gráfica, conforme destacado no Quadro 1.

Ao fazermos uma leitura vertical das produções escritas dos alunos vimos que esses têm uma dificuldade maior em resolver a atividade 5 do que a 1 , pois neste caso há interpretação de uma situação-problema. Assim, apresentamos a seguir algumas produções escritas de alunos e os signos que emergiram na resolução da atividade 5, conforme Figura 6.

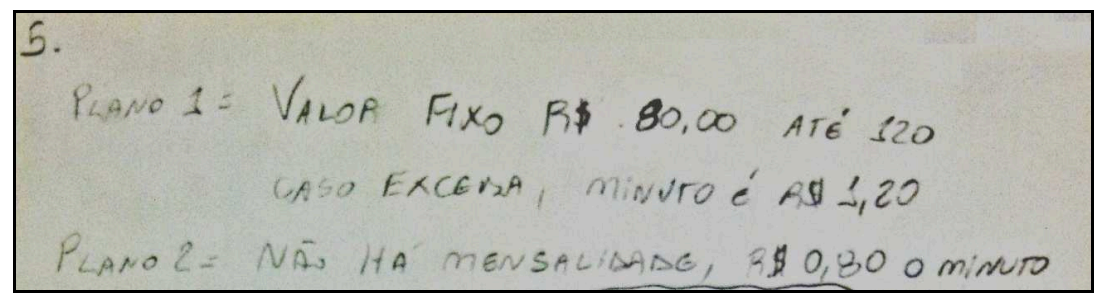

Figura 6 - Atividade 5 do aluno A16

Fonte: prova escrita do aluno A16.

O signo produzido por A16 se caracteriza como ícone, pois ainda que não apresente todo o enunciado da atividade, ele copia trechos do enunciado que considera para poder responder o problema (CP, 2.282).

O aluno apresenta também signos indiciais ao fazer os cálculos para responder à Atividade 5, conforme Figura 7.

Na produção dos signos algébricos, A16 faz uma interpretação matemática do enunciado do problema e uso de linguagem algébrica utilizando as expressões que já escreveu para cada um dos dois planos, conforme Figura 7. Além disso, para responder à atividade igualando as expressões para determinar em que momento será indiferente contratar qualquer um deles, signos indiciais se fazem necessários, pois se referem a uma singularidade das expressões gerais de cada plano (PEIRCE, 2012). 


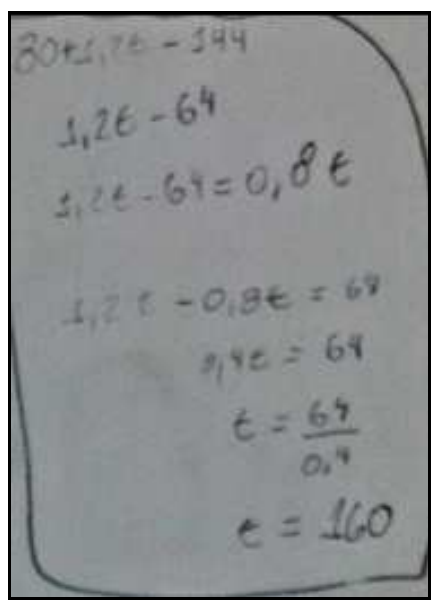

Figura 7 - Resposta da atividade 5 do aluno A16 Fonte: prova escrita do aluno A16.

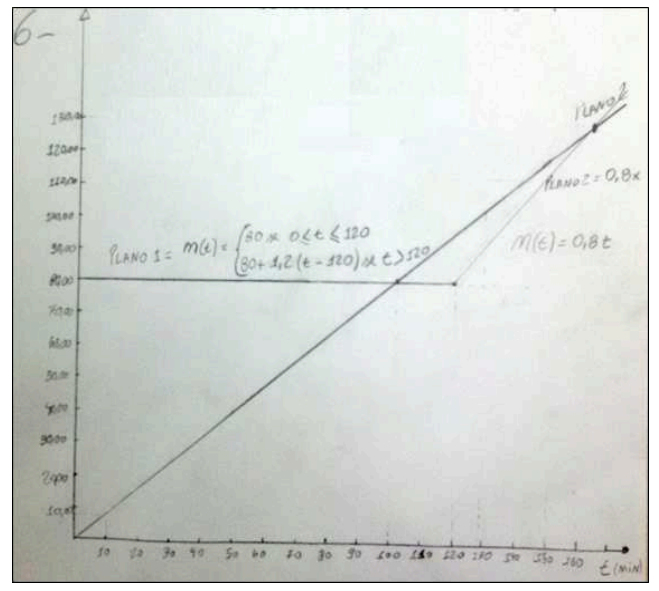

Figura 8 - Atividade 6 do aluno A16 Fonte: prova escrita do aluno A16.

$\mathrm{Na}$ atividade 6, nas expressões algébricas, como apresentado na Figura 8, A16 faz uso de signos simbólicos e o signo gráfico icônico. Assim, ao produzir signos que se portam como ícones, índices e símbolos A16 mostra por meio da produção escrita que consegue transcrever um problema de sua língua natural para a matemática, por meio de expressões algébricas e gráficas, que também respondem à atividade 6, e que também consegue associar o conceito de funções definidas por mais de uma sentença e faz o uso correto, por meio das operações aritméticas.

O aluno A27, por sua vez, não consegue estabelecer relações entre diferentes signos para se remeter ao objeto matemático em estudo. Na produção escrita para a atividade 5 , por tentativa e erro, apresenta signos indiciais ao escrever tabela para o Plano 1 e o Plano 2, pois esses signos remetem à situação descrita no enunciado.

Porém, ao apresentar um texto que responde a atividade, o aluno faz uma interpretação incorreta das tabelas que escreveu, pois, ao escrever: "Em até 100 minutos locais é indiferente contratar qualquer um dos dois, por ser o mesmo valor", A27 considera que até 100 minutos os valores pagos serão os mesmos, ainda que verifique por meio das tabelas que há diferenças, conforme Figura 9.

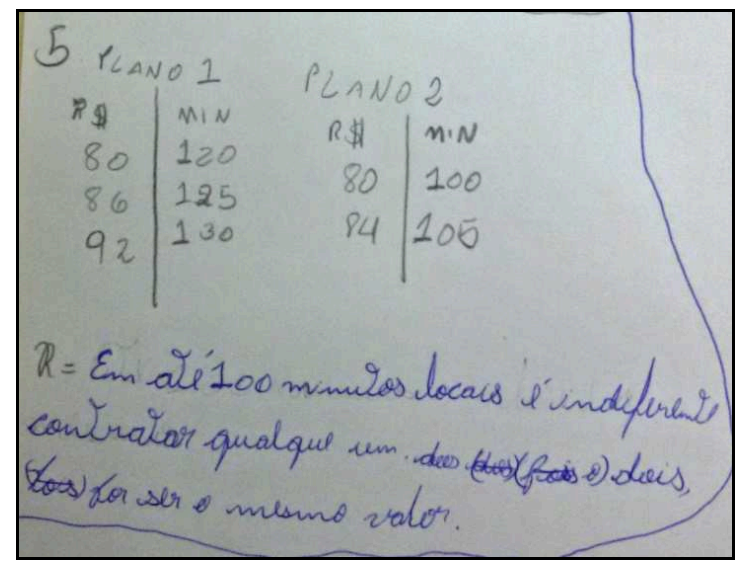

Figura 9 - Atividade 5 do aluno A27

Fonte: prova escrita do aluno A27. 
Ao fazermos uma leitura horizontal das atividades da turma, para a atividade retirada do livro didático de Matemática, conforme Tabela 6, nenhuma produção dos alunos fora agrupada como "Respondeu corretamente", mas a grande maioria ficou no agrupamento "Respondeu equivocadamente".

Tabela 6 - Agrupamento das resoluções da Atividade 5

\begin{tabular}{cc}
\hline Agrupamento & \multicolumn{1}{c}{ Produções } \\
\hline & \\
& A01ATIV05; A03ATIV05; A04ATIV05; A05ATIV05; A07ATIV05; \\
& A09ATIV05; A10ATIV05; A11ATIV05; A13ATIV05; A14ATIV05; \\
& A15ATIV05; A16ATIV05; A18ATIV05; A20ATIV05; A22ATIV05; \\
Responderam equivocadamente & A23ATIV05; A25ATIV05; A26ATIV05; A27ATIV05; A28ATIV05; \\
& A30ATIV05; A31ATIV05; A32ATIV05; A33ATIV05; A34ATIV05; \\
& A35ATIV05; A36ATIV05; A37ATIV05; A39ATIV05; A40ATIV05 \\
& \\
\hline & \\
\hline Não responderam & A02ATIV05; A06ATIV05; A08ATIV05; A12ATIV05; A17ATIV05; \\
& A19ATIV05; A21ATIV05; A24ATIV05; A29ATIV05; A38ATIV05 \\
\hline
\end{tabular}

Fonte: produzido pelos autores.

Olhando de maneira quantitativa para os dados agrupados, com as frequências e respectivas porcentagens de dados apresentamos a Tabela 7.

Tabela 7 - Dados quantitativos para o agrupamento da Atividade 5

\begin{tabular}{ccc}
\hline Agrupamento & Número de registros & Porcentagens em relação ao todo \\
\hline $\begin{array}{c}\text { Responderam } \\
\text { equivocadamente }\end{array}$ & 30 & 75 \\
\hline Não responderam & 10 & 25 \\
\hline
\end{tabular}

Fonte: produzido pelos autores.

O motivo de nenhuma produção ter sido agrupada como respondida corretamente foi que para a situação-problema "Uma operadora de celular oferece dois planos a seus clientes: plano I: valor fixo mensal de $R \$ 80,00$ para até 120 minutos de ligações locais. Caso o cliente exceda esse tempo, o custo do minuto adicional é de $R \$ 1,20$; plano II: não há mensalidade e cada ligação local custa $R \$ 0,80$. Para quantos minutos de ligações locais no mês é indiferente contratar qualquer um dos planos?" haviam duas possíveis respostas: para 100 minutos ou 160 minutos é indiferente contratar qualquer um dos planos, mas nenhum dos alunos conseguiu obter esses dois valores de minutos.

Dos 30 alunos que estão no agrupamento "Responderam equivocadamente", 10 responderam ao problema dizendo que é indiferente contratar qualquer um dos planos para 160 minutos e cinco alunos responderam que é indiferente a contratação de qualquer plano para 100 minutos. Entretanto, ao traçar um perfil da turma na resolução dessa atividade, percebe-se que os alunos ao invés de responderem "para quantos minutos de ligações locais 
no mês é indiferente contratar qualquer um dos planos?" possivelmente tentaram responder "a partir de determinado tempo, qual dos planos é mais vantajoso?". Sendo assim, parece que o Problema Resolvido pelo aluno foi diferente do Problema Proposto para ser resolvido. Segundo Dalto e Buriasco (2009):

Considera-se Problema Proposto aquele que constava originalmente na Prova e que se esperava que fosse resolvido pelo estudante, e Problema Resolvido aquele que, mediante a produção escrita, inferiu-se que cada estudante resolveu como resultado da interpretação que fez do Problema Proposto (DALTO; BURIASCO, 2009, p. 456).

Assim, se considerarmos as resoluções de boa parte dos alunos, podemos concluir que as respostas poderiam ser agrupadas como corretas para o problema que foi resolvido, mas não ao problema que foi proposto para que resolvessem (DALTO; BURIASCO, 2009).

O que acontece nas produções da atividade 5 da prova é refletido também na atividade 6 que explora a parte gráfica da situação retirada do livro didático, pois praticamente metade dos discentes não respondeu à atividade, conforme Tabela 8.

Tabela 8 - Agrupamento das resoluções da atividade 6

\begin{tabular}{cc}
\hline \multicolumn{1}{c}{ Agrupamento } & Produções \\
\hline Responderam corretamente & A16ATIV06; A30ATIV06; A31ATIV06 \\
\hline Responderam equivocadamente & $\begin{array}{c}\text { A14ATIV06; A15ATIV06; A18ATIV06; A22ATIV06; A23ATIV06; } \\
\text { A26ATIV06; A28ATIV06; A32ATIV06; A33ATIV06; A34ATIV06; } \\
\end{array}$ \\
& A35ATIV06; A39ATIV06; A40ATIV06 \\
\hline Não responderam & A02ATIV06; A06ATIV06; A07ATIV06; A08ATIV06; A10ATIV06; \\
& A11ATIV06; A12ATIV06; A13ATIV06; A17ATIV06; A19ATIV06; \\
& A20ATIV06; A21ATIV06; A24ATIV06; A25ATIV06; A27ATIV06; \\
& A29ATIV06; A36ATIV06; A37ATIV06; A38ATIV06 \\
\hline
\end{tabular}

Fonte: produzido pelos autores.

O que podemos observar é que praticamente a outra metade dos estudantes respondeu com equívocos, conforme Tabela 9.

Tabela 9 - Dados quantitativos para o agrupamento da Atividade 6

\begin{tabular}{ccc}
\hline Agrupamento & Número de registros & Porcentagens em relação ao todo \\
\hline $\begin{array}{c}\text { Responderam } \\
\text { Corretamente }\end{array}$ & 03 & 7,5 \\
\hline $\begin{array}{c}\text { Responderam } \\
\text { equivocadamente }\end{array}$ & 18 & 45 \\
\hline Não responderam & 19 & 47,5 \\
\hline
\end{tabular}

Fonte: produzido pelos autores.

A partir das produções escritas dos alunos identificamos alguns erros que eles cometeram na hora de resolver a atividade 6 da prova, conforme Tabela 10 . 
Tabela 10 - Tipos de erros percebidos na atividade 6

\begin{tabular}{c|r}
\hline Produções & Tipos de erro \\
\hline A18ATIV06; & \\
A23ATIV06; & Representou graficamente uma única reta \\
A35ATIV06 & \\
\hline A05ATIV06; & Representou graficamente uma curva \\
A09ATIV06; & \\
A26ATIV06 & \\
\hline A03ATIV06; & \\
A14ATIV06; & \\
A33ATIV06 & Representou graficamente quase corretamente o gráfico, mas com intercessões em pontos não corretos \\
\hline A01ATIV06; & \\
A28ATIV06; & \\
A39ATIV06; & Representou graficamente como duas retas que se interceptam em determinado ponto \\
A40ATIV06 & Representou graficamente retas com intervalos abertos e fechados \\
\hline A04ATIV06; & \\
A34ATIV06 & Representou graficamente para cada plano de celular um gráfico em um plano diferente \\
\hline A22ATIV06; & Representou graficamente duas retas sem marcação alguma \\
A32ATIV06 & Fonte producido pelos autores. \\
\hline A15ATIV06 &
\end{tabular}
Fonte: produzido pelos autores.

\section{Ponderações finais}

Apesar de o conceito de funções definidas por mais de uma sentença estar presente no currículo do Ensino Médio, inferimos, por meio da Análise da Produção Escrita de estudantes do Ensino Superior na disciplina de Cálculo que ainda há fragilidade neste conceito. Podemos evidenciar isso a partir das leituras (vertical e horizontal) feita das atividades, pois muitos alunos não conseguiram associar valores numéricos a sentença correta da função, ou então conseguiram fazer uma representação gráfica correta.

Além disso, houve dificuldades de manipulações aritméticas e algébricas, como alguns alunos não conseguiram associar o número $\sqrt{3}$ à sentença correta da função, ou então encontraram como respostas para os itens da atividade 1 expressões algébricas quando deveriam obter um número.

Houve também divergência na interpretação do enunciado da atividade 5, pois muitos alunos responderam a um problema diferente daquele que fora proposto. Se o problema resolvido fosse o mesmo que o problema proposto, muitos alunos que tiveram suas produções desta atividade agrupadas como "responderam equivocadamente" poderiam ser agrupados para "responderam corretamente", pois encontraram uma das duas respostas corretas possíveis para o problema proposto.

A interpretação que fazemos a partir das análises é de que o conceito de funções definidas por mais de uma sentença deve ser tratado e explorado, se não no Ensino Médio, no Ensino Superior, mostrando como associar valores numéricos a sentenças corretas e como cada sentença influencia no gráfico que será representado. 
A análise semiótica dos signos produzidos pelos alunos também se mostra uma ferramenta potencial para o professor, pois permite que o mesmo estabeleça relações, evidenciando quais são os erros cometidos pelos alunos, seja relativo ao entendimento do conteúdo ou à forma como os alunos apresentam as notações matemáticas para o conteúdo. Com isso, o professor pode inferir como os alunos entendem determinado conceito pelo modo como produzem os signos.

Contudo a análise semiótica empreendida pode ser enriquecida considerando signos falados e gesticulados que permitem uma análise mais complexa dos significados atribuídos pelos alunos a respeito dos conteúdos matemáticos estudados.

Os signos falados e gesticulados, complementando os registros escritos, podem esclarecer para o professor os entendimentos e dificuldades dos alunos, como por exemplo, responder ao Problema Proposto ao invés do Problema Resolvido. Casos em que o aluno consegue expressar seus conhecimentos por meio de uma linguagem não matemática, permite ao professor traçar uma estratégia de formalização em que auxilia o aluno a "traduzir" para a linguagem matemática.

Em relação à Análise da Produção Escrita destacamos as possibilidades do professor estabelecer perfis individuais e de forma global de uma turma de alunos a partir dos registros escritos produzidos por estudantes podendo destacar possíveis erros comuns a uma parte do grupo de alunos, ou ainda dificuldades que um mesmo discente tem ao resolver atividades que podem ser resolvidas por estratégias semelhantes. Diante dos resultados obtidos com a análise da produção escrita, o professor alterou sua metodologia e retomou o conteúdo com os alunos de forma a esclarecer os conceitos abordados, bem como a forma de representá-los.

No caso deste artigo, a partir das leituras horizontais e verticais pudemos traçar os perfis dos alunos e da turma a respeito do conteúdo de funções definidas por mais de uma sentença, verificar se um mesmo aluno tem dificuldades em resolver uma questão estritamente matemática ou ainda se o mesmo tem dificuldades em uma questão contextualizada, quais foram os erros comuns a toda turma e o que poderia ter condicionado uma interpretação equivocada por parte dos alunos e as conclusões que podem ser feitas a partir de tudo isto.

Todavia, o que almejamos neste artigo foi mostrar as potencialidades da Análise da Produção Escrita em aulas de Matemática como uma prática de investigação que permite os alunos revelar seus conhecimentos ao mesmo tempo revelar para o professor suas dificuldades para que possa intervir e modificar o planejamento das aulas visando uma melhoria nos processos de ensino e de aprendizagem em sala de aula. Tais intervenções podem estar relacionadas à metodologia empregada nas aulas e na forma como elabora suas provas, 
considerando os enunciados das atividades, bem como uma negociação da forma como escrevem matematicamente o conteúdo.

Embora nesta pesquisa tenhamos sinalizado fragilidades dos alunos, em nossas aulas temos nos empenhado em desenvolver atividades e encaminhamentos no sentido de superálas, considerando, para além dos registros escritos, os falados e os gesticulados quando os alunos trabalham em grupos. Para tanto, fazemos uso de alternativas pedagógicas, como a Modelagem Matemática (SILVA; DALTO, 2017, SILVA; ALMEIDA, 2017, SILVA, 2017, ALMEIDA; SILVA, 2017, VERTUAN; SILVA; BORSSOI, 2017, SILVA, 2018, DALTO; SILVA, 2018), em que situações-problema relativas ao curso no qual os alunos estão inseridos consistem o mote para emergir conteúdos matemáticos da disciplina de Cálculo, em específico, aqueles voltados para o estudo de funções.

\section{Referências}

ALMEIDA, V. L. C. Questões não-rotineiras: a produção escrita de alunos da graduação em Matemática. 2009. 144f. Dissertação (Mestrado em Ensino de Ciências e Educação Matemática) - Universidade Estadual de Londrina, Londrina. 2009.

ALMEIDA, L. M. W.; SILVA, K. A. P. A Ação dos Signos e o Conhecimento dos Alunos em Atividades de Modelagem Matemática. Bolema, v. 31, n. 57, p. 202-219, 2017.

BOGDAN, R., BIKLEN, S. Investigação Qualitativa em Educação: uma introdução à teoria e aos métodos. Porto: Porto Editora, 1994.

BOUGNOUX, D. Introdução às ciências da comunicação. São Paulo: Edusc, 1999.

BRASIL. Ministério da Educação. PNLD 2018: Matemática - guia de livros didáticos Ensino Médio. Ministério da Educação, Secretária de Educação Básica, SEB Fundo Nacional de Desenvolvimento da Educação. Brasília, DF: Ministério da Educação, Secretária de Educação Básica, 2017.

CELESTE, L. B. A produção escrita de alunos do Ensino Fundamental em questões de matemática do PISA. Dissertação de mestrado em Ensino de Ciências e Educação Matemática, Universidade Estadual de Londrina, Londrina, 2008.

DALTO, J. O. A Produção Escrita em Matemática: análise interpretativa da questão discursiva de Matemática comum à $8^{\mathrm{a}}$ série do Ensino Fundamental e à $3^{\mathrm{a}}$ série do Ensino Médio da AVA/2002. Dissertação de mestrado em Ensino de Ciências e Educação Matemática, Universidade Estadual de Londrina, Londrina, Brasil, 2007.

DALTO, J. O.; BURIASCO, R. L. C. Problema proposto ou problema resolvido: Qual a diferença?. Educação e Pesquisa, v. 35, n. 3, p. 449-461, 2009.

DALTO, J. O.; SILVA, K. A. P. Atividade de Modelagem Matemática como Estratégia de Avaliação da Aprendizagem. Educação Matemática em Revista, v. 23, n. 57, p. 34-45, 2018.

DANTE, L. R. Matemática: contextos e aplicações - ensino médio, volume 1. 3. ed., São Paulo: Ática, 2016. 
IEZZI, G.; DOLCE, O.; DEGENSZAJN, D.; PÉRIGO, R.; ALMEIDA, N.Matemática: ciências e aplicações - ensino médio, volume 1. 9. ed., São Paulo: Saraiva, 2016.

MODERNA (Organizadora). Conexões com a Matemática. 3. ed., São Paulo: Moderna, 2016.

NIEMEYER, L. Elementos de Semiótica aplicados ao design. Rio de Janeiro: 2AB, 2003.

NÖTH, W. Panorama da Semiótica: de Platão a Peirce. 4. ed. São Paulo: Annablume, 2008.

OTTE, M. Mathematical epistemology from a semiotic point of view. In: PME International Conference, 25, University of Utrecht, The Netherlands, 2001.

PAIVA, M. Matemática: Paiva. 3. ed., São Paulo: Moderna, 2015.

PEIRCE, C. S. Collected papers. Vols, 1-6 organizados por Charles Hartshorne \& Paul Weiss; vols 7-8 organizados por Arthur W. Burks. Cambridge, Mass, Havard Uni. Press, 1931-58.

PEIRCE, C. S. Semiótica. São Paulo: Editora Perspectiva, 2012.

PIGNATARI, D. Informação, linguagem, comunicação. 2. ed. São Paulo: Culturix, 1981.

PIRES, M. N. M. Oportunidade para aprender: uma prática da reinvenção guiada na prova em fases. 2013.122 f. Tese (Doutorado em Ensino de Ciências e educação matemática) Universidade Estadual de Londrina, Londrina, 2013.

SANTAELLA, L. Semiótica aplicada. São Paulo: Thomson Learning, 2007.

SANTOS, E. R. Estudo da produção escrita de alunos do Ensino Médio em questões discursivas não rotineiras de matemática. 2008. 166f. Dissertação (Mestrado em Ensino de Ciências e Educação Matemática) - Universidade Estadual de Londrina, Londrina. 2008.

SANTOS, E. R.; BURIASCO, R. L. C. Análise da Produção Escrita em Matemática como uma Estratégia de Ensino: algumas considerações. Educação Matemática Pesquisa, v. 17, n. 1, p. 119-136, 2015.

SANTOS, E. R.; BURIASCO, R. L. C. A análise da produção escrita em Matemática como estratégia de avaliação: aspectos de uma caracterização a partir dos trabalhos do GEPEMA. Alexandria: Revista de Educação em Ciência e Tecnologia, v. 9, n. 2, p. 233-247, 2016.

SILVA, K. A. P.. Aspectos Cognitivos em Aulas com Modelagem Matemática na Disciplina de Cálculo Diferencial e Integral. Experiências em Ensino de Ciências, v. 12, n. 2, p. 156$170,2017$.

SILVA, K. A. P. Modelagem matemática em aulas de cálculo diferencial e integral: para além de uma investigação. Educação Matemática em Revista, v. 1, n. 19, p. 93-104, 2018.

SILVA, K. A. P.; ALMEIDA, L. M. W. Percepção da Matemática em atividades de modelagem matemática. Vidya, v. 37, n. 1, p. 109-125, 2017.

SILVA, K. A. P.; DALTO, J. O. Uma estratégia de Avaliação de Atividades de Modelagem Matemática. Revista Electrónica de Investigación en Educación en Ciencias (en línea), v. 12, n. 2, p. 1-17, 2017. 
SMOLE, K. S.; DINIZ, M. I. Matemática para compreender o mundo 1. 1. ed., São Paulo: Saraiva, 2016.

VERTUAN, R. E.; SILVA, K. A. P.; BORSSOI, A. H. Modelagem Matemática em disciplinas do Ensino Superior: o que manifestam os estudantes?. Educere et Educare (Impresso), v. 12, n. 24, p. 1-15, 2017.

\section{SOBRE OS AUTORES}

VICTOR HUGO DOS SANTOS GOIS. Licenciado em Matemática pela Universidade Estadual de Londrina (UEL). Especialista em Ensino de Ciências e Matemática pela Universidade Tecnológica Federal do Paraná (UTFPR), Campus Londrina. Mestrando em Ensino de Matemática do Mestrado Profissional também pela Universidade Tecnológica Federal do Paraná, Londrina - Cornélio Procópio.

KARINA ALESSANDRA PESSOA DA SILVA. Professora da Universidade Tecnológica Federal do Paraná, Campus Londrina, atuando nos cursos de Licenciatura em Química e Engenharia de Produção e no Programa de Pós-Graduação Mestrado Profissional em Ensino de Matemática (PPGMAT). Graduada em Matemática (Licenciatura) pela Universidade Estadual de Londrina (2000). Especialista em Educação Matemática pela UEL (2007). Mestre e Doutora em Ensino de Ciências e Educação Matemática pela Universidade Estadual de Londrina (2013). É uma das coordenadoras do Grupo de Estudos e Pesquisas em Modelagem, Investigação e Tecnologia (GEPMIT) / UTFPR.

JADER OTAVIO DALTO. Professor Adjunto do Departamento Acadêmico de Matemática da Universidade Tecnológica Federal do Paraná - Campus Cornélio Procópio. Atua no Programa de Pós-Graduação Mestrado Profissional em Ensino de Matemática (PPGMAT). Mestre e Doutor em Ensino de Ciências e Educação Matemática pela Universidade Estadual de Londrina.

Recebido: 21 de fevereiro de 2018.

Revisado: 12 de agosto de 2018.

Aceito: 13 de setembro de 2018. 